\title{
An Internally-controlled Double Blind Trial of Thalidomide in Severe Erythema Nodosum Leprosum*
}

\author{
M. F. R. WATERS \\ Leprosy Research Unit, Sungei Buloh Leprosarium, Selangor, Malaysia \\ and \\ National Institute for Medical Research, Mill Hill, London, N.W.7, England $\dagger$
}

\begin{abstract}
A double-blind, internally-controlled, clinical trial of thalidomide in severe, chronic, histologically-proven erythema nodosum leprosum (ENL) is reported. A total of 10 adult male patients were admitted to the trial, all of whom were receiving continuous treatment with steroids and whose minimum daily requirement just to suppress the reaction was in no case less than $15 \mathrm{mg}$ of prednisolone or 18 international units of corticotrophin. The trial was divided into 4 equal parts (of either 4 or 6 weeks' duration) consisting of an initial control period, first and second trial periods, and a final control period. Throughout the trial all patients received DDS, $100 \mathrm{mg}$ twice weekly; thalidomide, $300 \mathrm{mg}$ daily, was given during one trial period and identical placebo tablets during the other. As judged by the reduction in their steroid requirements, 9 of the 10 patients showed a very significant improvement while they were receiving thalidomide, although 7 subsequently relapsed after stopping the drug. There was no dose-for-dose relationship between thalidomide and prednisolone. Two patients developed a mild allergic dermatitis.
\end{abstract}

\section{Introduction}

Since the discovery by Sheskin $(1965 a, b, c)$ that thalidomide has a beneficial effect on lepromatous lepra reactions, a number of communications have been published confirming the value of the drug in suppressing erythema nodosum leprosum (ENL). However, with the notable exception of the series reported by Sheskin and his colleagues (Sheskin, 1965a, b; Sheskin and Convit, 1966, 1969; Sheskin and Sagher, 1968) most of the studies have been uncontrolled.

In South-east Asia ENL is particularly common, developing in more than 50\% of lepromatous patients within a year of their beginning anti-leprosy treatment (Waters et al., 1967); frequently the reactions are severe. Therefore it was considered important to assess more precisely, by means of an internallycontrolled double-blind trial, the effect of thalidomide in patients with well-defined lepromatous leprosy, suffering from severe, histologically-proven ENL. Only those patients whose reactions required at least $15 \mathrm{mg}$ of prednisolone

* A brief account of this trial was presented at the Ninth International Leprosy Congress, London (Waters, 1968).

$\dagger$ Request for reprints should be sent to this address. 
or 18 international units (IU) of corticotrophin (ACTH) daily for control of symptoms were admitted to the trial. Additional objectives included an assessment of the rate at which steroid dosage could be reduced in such patients after the introduction of thalidomide treatment, and whether in ENL there was any dose-for-dose relationship between steroids and thalidomide.

After this study was initiated, a second double-blind trial was carried out of the effect of thalidomide on less severe ENL; the results were earlier reported by Pearson and Vedagiri (1969).

\section{Materials and Methods}

\section{INTAKE AND PRELIMINARY INVESTIGATIONS}

Ten adult male patients aged 19 to 56 were admitted to the trial (Table 1). Post-menopausal females were also considered suitable, but none were available at the time of intake; of the 10 patients 6 were ethnically Chinese, 2 Malay and 2 Southern Indian. Clinically, all were lepromatous; histopathologically, 5 were pure lepromatous (LL) and 5 were indefinite lepromatous (LI) (Ridley and Jopling, 1966; Ridley and Waters, 1969). All were suffering from histologically confirmed, moderately severe or severe chronic ENL, 2 patients being graded ,$++++ 7+++$ and $1++/+++$ (Waters, 1963). All required treatment with steroids, the average daily dose ( 9 patients) being $28 \mathrm{mg}$ prednisolone (range 15 to $52.5 \mathrm{mg}$ ); 1 patient (no. 8), probably the mildest case of the 10 , was receiving corticotrophin in an average dose of 20 IU daily. The duration of the ENL at time of intake varied from 9 months to $3 \frac{1}{2}$ years; that of steroid therapy averaged 12 months (range 1 to 23 months). All the patients were receiving dapsone (DDS) in various doses; the duration of anti-leprosy treatment ranged from 1 year 8 months to 3 years 10 months. Details of the cases are presented in Table 1.

Each patient was admitted to the Leprosy Research Unit wards, and spent the period of the trial in hospital. Pre-trial investigations included complete clinical examination, urine testing, X-ray of chest (unless performed within the previous 6 months), weight of patient, haemoglobin estimation, and white blood cell and differential cell counts. At the clinical examination, both the state of the lepromatous leprosy and the nature and distribution of the ENL lesions were noted, and colour photographs were taken. Unless previous reports were available, skin biopsies were performed to confirm the type of leprosy, and also that the reaction was indeed ENL. Smears were taken from both ears and from 4 skin sites, and the Bacteriological Index (BI), using Ridley's logarithmic scale, and the Morphological Index (MI) (Waters et al., 1967) were determined. Intradermal tests were performed with lepromin (Wade-Mitsuda type) and tuberculin (1 TU of RT 23), unless they had previously been carried out within 6 months of admission to the trial.

\section{THERAPY}

All patients were standardized on $100 \mathrm{mg}$ of DDS twice weekly by mouth, and this dose was left unchanged throughout the trial. In addition, all received either prednisolone ( 9 patients) or corticotrophin ( 1 patient) in daily doses designed to be just sufficient to suppress the reaction. Each patient was seen daily (except on Sundays) by the author, and the minimum dose of steroid was prescribed which it was estimated would control fever and reduce the number and frequency of ENL lesions to acceptable levels. In general, worsening of the symptoms was treated by 
TABLE 1

Clinical details of the 10 patients admitted to the trial

\begin{tabular}{|c|c|c|c|c|c|c|c|c|c|}
\hline \multirow{2}{*}{$\begin{array}{l}\text { Patient } \\
\text { no. }\end{array}$} & \multirow{2}{*}{ Age } & \multirow{2}{*}{ Race $^{a}$} & \multirow{2}{*}{$\begin{array}{c}\text { Classification } \\
\text { of } \\
\text { leprosy }^{b}\end{array}$} & \multicolumn{2}{|c|}{ Smears } & \multirow{2}{*}{$\begin{array}{c}\text { Severity } \\
\text { of } \\
\text { ENL }^{e}\end{array}$} & \multicolumn{3}{|c|}{ Duration (months) of } \\
\hline & & & & $\mathrm{BI}^{c}$ & $\mathrm{MI}^{d}$ & & $\begin{array}{l}\text { Leprosy } \\
\text { treatment }\end{array}$ & ENL & $\begin{array}{c}\text { Continuous steroid } \\
\text { treatment }\end{array}$ \\
\hline 1 & 34 & $\mathrm{C}$ & LI & 4.3 & 0 & +++ & 46 & 42 & 15 \\
\hline 2 & 51 & $\mathrm{C}$ & LL & 3.3 & 0 & +++ & 30 & 25 & 15 \\
\hline 3 & 32 & M & LI & 4.3 & 0 & ++++ & 23 & 9 & 9 \\
\hline 4 & 21 & $\mathrm{C}$ & $\mathrm{LL}$ & 4.2 & 0 & +++ & 22 & 20 & 9 \\
\hline 6 & 19 & M & LL & 4.7 & 0 & ++++ & 30 & 26 & 23 \\
\hline 7 & 44 & I & LL & 3.5 & 0 & +++ & 44 & 27 & 14 \\
\hline 8 & 56 & $\mathrm{C}$ & LI & 4.0 & 0 & $++/+++$ & 26 & 18 & 14 \\
\hline 9 & 51 & $\mathrm{C}$ & LI & 5.0 & 1 & ++ & 20 & 17 & 2 \\
\hline 10 & 28 & I & LL & 4.2 & 0 & +++ & $24^{f}$ & $26^{f}$ & 1 \\
\hline
\end{tabular}

${ }^{a} \mathrm{C}=$ Chinese $\mathrm{I}$ = Indian; $\mathrm{M}=$ Malay.

${ }^{b} \mathrm{LL}=$ Pure lepromatous; LI = Indefinite lepromatous (Ridley and Jopling, 1966; Ridley and Waters, 1969).

$c$ Bacteriological Index (Ridley's logarithmic scale).

$d$ Morphological Index.

e Graded according to Waters (1963).

$f$ This patient was treated for leprosy from 1952 to 1957 ; data of relapse uncertain, as are treatment details between 1957 and 1966. 
raising the daily dose of prednisolone, but this was sometimes supplemented by giving one or a small number of corticotrophin injections. Whenever symptoms improved, the dose of steroid was reduced.

Thalidomide was supplied in 100-mg tablets, coded "B". Placebo tablets of identical appearance were labelled " $A$ ". The code was not revealed to anyone in Malaysia until after the trial was completed. During the appropriate periods of the trial (vide infra) either 1 thalidomide or 1 placebo tablet was given 3 times daily. All tablets were taken in the presence of nursing staff.

Stibophen was not given to the trial patients (unless they were receiving neither steroids nor thalidomide). Mild analgesic drugs such as aspirin and paracetamol were freely prescribed when symptomatically indicated.

\section{ORGANIZATION OF THE TRIAL}

(a) First series. Sixteen weeks schedule. The trial was designed to consist of 4 separate but continuous treatment periods of 4 weeks each, as follows:

Period 1. Weeks 1-4.

Period 2. Weeks 5-8.

Period 3. Weeks 9-12.
First control period, no added treatment.

First trial period; tablet " $\mathrm{A}$ " or "B" given 3 times daily.

Second trial period; tablet " $\mathrm{B}$ " or " $\mathrm{A}$ " given daily (reverse of Period 2).

Period 4. Weeks 13-16. Final control period; no added treatment.

A series of sealed envelopes was prepared, containing the letter " $A$ " or the letter " $B$ " by random distribution. The decision whether a patient received tablet " $A$ " or " $B$ " throughout Period 2 (and vice versa in Period 3) was made according to the letter given in the next envelope in the series. The envelope was opened by the Leprosy Research Unit worker not running the trial, and he and the Unit Secretary dispensed the appropriate tablets, a week's supply at a time, to the ward in a bottle labelled only with the patient's name, number, and study number. At no time throughout the trial did the doctor-in-charge know who was receiving tablets " $A$ " or " $B$ ", and the nursing staff and patients were not aware that 2 different tablets were being used.

(b) Second series. Twenty-four weeks schedule. Patients nos. 1 to 9 were all admitted to the 16-week trial schedule. However, after the intake of patient no. 9 it was realized, from a sequential analysis of the results, that the prednisolone requirements of patients receiving the active (presumed thalidomide) preparations were still falling at the end of the 4-week period and had not reached a base-line level. Therefore a second study, similar to the first study but consisting of 4 consecutive 6-week periods was devised as follows:

$\begin{array}{ll}\text { Period 1. Weeks 1-6. } & \text { First control period. } \\ \text { Period 2. Weeks 7-12. } & \text { First trial period. } \\ \text { Period 3. Weeks 13-18. } & \text { Second trial period. } \\ \text { Period 4. Weeks 19-24. } & \text { Final control period. }\end{array}$

Patient no. 10 was entered for the 24-week trial only; in addition, patients nos. 1 to 7 , who had completed the first trial schedule, were admitted to the second, 24-week, schedule. Once again, random selection was used to decide whether tablet " $A$ " or " $B$ " was given first. Patient no. 8 was omitted because by the end of the 16-week schedule, his ENL had so improved that he no longer satisfied the admission criteria. Patient no. 9 was also omitted, in this case because his ENL 
had been so variable and unstable that his prednisolone requirements showed wide fluctuations during the 16-week trial; furthermore, for social reasons he wished to be discharged from hospital.

The same personnel were responsible for the second schedule as for the first, the same investigations and assessments were carried out, and the same methods of analysis were used in both studies.

\section{INVESTIGATIONS AND ASSESSMENTS DURING THE TRIAL}

The temperature of each patient was taken routinely, 5 times daily. The severity of each patient's reaction was noted daily (except Sundays) by the author. At the end of each week a summary of the week's clinical findings was made, together with an overall assessment of the severity of each patient's ENL. Full leprosy examinations were carried out at the end of each 4- or 6-week trial period, and complete clinical examination at the end of the trial schedule.

Patients were weighed every week. Haemoglobin estimation and white blood cell and differential counts were normally performed fortnightly. Urines were checked weekly for albumin, and laboratory urinalysis was carried out every 4 weeks.

\section{ANALYSES}

The analyses compare the 4 treatment periods in each patient. In both schedules, there were 2 effective control periods (the first and either the second or the fourth); thalidomide was given during either the second or the third period, and the subsequent period (either third or fourth) demonstrated the speed at which the effects of the drug subsided after its withdrawal. The assessments were made on the total dose of steroid prescribed, the temperature, the clinical condition, and the white blood cell count.

The principal assessment was based on the total dosage of steroids prescribed per week in each period; for uniformity of presentation, this has been expressed in mg of prednisolone. Aqueous corticotrophin, given in small supplemental doses to patients receiving oral prednisolone, has been converted in the analysis at the arbitrary rate of $2 \mathrm{IU}$ of corticotrophin to $1 \mathrm{mg}$ of prednisolone. Prednisolone given by injection has been scored, milligram for milligram, as equivalent to oral prednisolone; hydrocortisone given by injection has been scored on the basis that $5 \mathrm{mg}$ of the drug was equivalent to $1 \mathrm{mg}$ of prednisolone, and $1 \mathrm{mg}$ of betamethasone was considered as equivalent to $8 \mathrm{mg}$ of prednisolone (these 3 drugs were all given to patient no. 1 during a very severe exacerbation of his ENL). For the one patient (no. 8) who received corticotrophin only, dosage is expressed in international units of corticotrophin and no notational conversion to prednisolone has been attempted.

The highest temperature recorded each day for each patient was scored as follows:

Temperature below $\quad \begin{array}{ll}99^{\circ} \mathrm{F}\left(37.2^{\circ} \mathrm{C}\right) & =0 \\ 99 \text { to } 99.8^{\circ} \mathrm{F}\left(37.2 \text { to } 37.7^{\circ} \mathrm{C}\right) & =1 \text { point } \\ 100 \text { to } 100.8^{\circ} \mathrm{F}\left(37.8 \text { to } 38.2^{\circ} \mathrm{C}\right) & =2 \text { points } \\ 101 \text { to } 101.8^{\circ} \mathrm{F}\left(38.3 \text { to } 38.8^{\circ} \mathrm{C}\right) & =3 \text { points } \\ 102 \text { to } 102.8^{\circ} \mathrm{F}\left(38.9 \text { to } 39.3^{\circ} \mathrm{C}\right) & =4 \text { points } \\ 103 \text { to } 103.8^{\circ} \mathrm{F}\left(39.4 \text { to } 39.9^{\circ} \mathrm{C}\right) & =5 \text { points } \\ 104^{\circ} \mathrm{F}\left(40^{\circ} \mathrm{C}\right) \text { and over } & =6 \text { points }\end{array}$

Daily temperature points were added together to give weekly aggregate scores. 
The weekly assessment of the severity of each patient's ENL could not be graded according to our previous scale (Waters, 1963), as this was dependent on steroid dosage unmodified by other drugs. Therefore, in this trial the severity of the ENL was scored according to the following criteria:

Grade 0: no new ENL lesions; no evidence of active reaction or neuritis.

Grade 1: $\quad$ very mild; relatively sparse, scattered ENL papules; temperature below $99^{\circ} \mathrm{F}\left(37.2^{\circ} \mathrm{C}\right)$.

Grade 2: mild ENL; fairly numerous but discrete ENL papules occasional mild fever.

Grade 3: moderate ENL; widespread ENL papules; moderate general malaise, with fever to approximately $102^{\circ} \mathrm{F}\left(38.9^{\circ} \mathrm{C}\right)$; alternatively, pustular or necrotic ENL with little or no fever.

Grade 4: $\quad$ severe ENL; widespread ENL papules, which may be necrotic or pustular, associated with marked general malaise and high fever to approximately $103^{\circ} \mathrm{F}\left(39.4^{\circ} \mathrm{C}\right)$.

Grade 5: extremely severe ENL, very ill patient with continuous high fever over $103^{\circ} \mathrm{F}\left(39.4^{\circ} \mathrm{C}\right)$; necrotic or pustular ENL, often with coalescing lesions; very severe malaise and prostration.

Although subjective, these assessments were all made by the same worker, and it was possible to achieve consistent and uniform scoring.

The total white blood cell counts were not scored, but the actual figures were examined to see if they bore any obvious relationship to the giving of thalidomide.

\section{SIXTEEN-WEEK STUDY}

\section{Results}

Steroid requirements. The weekly steroid requirements for all 9 patients admitted to the 16-week schedule are shown in Table 2, and those for 1 representative patient (no. 4) are illustrated in Fig. 1. Patients nos. 2, 4, 7, 8 and 9 received thalidomide in Period 2 (weeks 5 to 8 ), whereas patients nos. 1, 3, 5 and 6 received the trial drug in Period 3 (weeks 9 to 12 ).

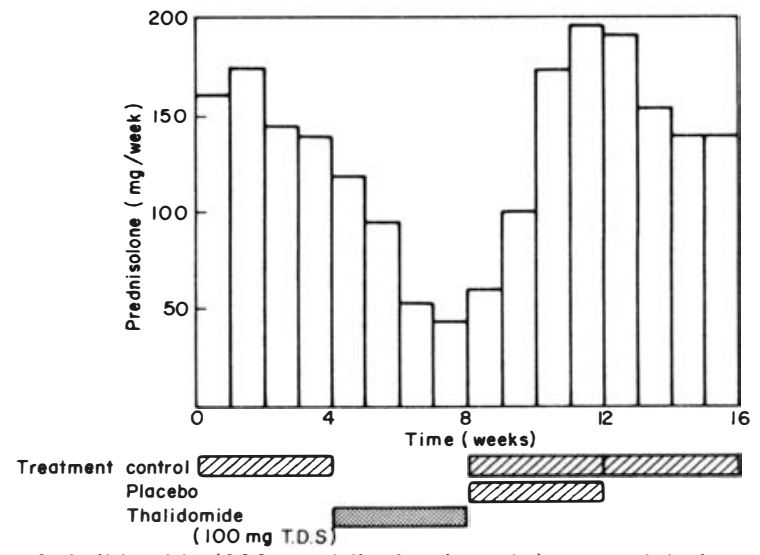

Fig. 1. Effect of thalidomide $(300 \mathrm{mg}$ daily for 4 weeks) on prednisolone dosage in severe chronic erythema nodosum leprosum. Double-blind trial, 16-week schedule; patient no. 4. 
TABLE 2

Total weekly steroid dosage prescribed for each of the 9 patients in the 16-week trial schedule

\begin{tabular}{|c|c|c|c|c|c|c|c|c|c|c|c|c|c|c|c|c|}
\hline \multirow{2}{*}{$\begin{array}{c}\text { Patient } \\
\text { no. }^{a}\end{array}$} & \multicolumn{16}{|c|}{ Total weekly steroid dosage (expressed in $\mathrm{mg}$ of prednisolone ${ }^{b}$ ) in trial week no.: } \\
\hline & 1 & 2 & 3 & 4 & 5 & 6 & 7 & 8 & 9 & 10 & 11 & 12 & 13 & 14 & 15 & 16 \\
\hline 2 & 135 & 123 & 105 & 140 & 140 & 98 & 75 & 48 & 70 & 83 & 105 & 105 & 105 & 95 & 124 & 135 \\
\hline 4 & 161 & 175 & 145 & 140 & 118 & 93 & 53 & 43 & 58 & 100 & 173 & 196 & 190 & 153 & 140 & 140 \\
\hline 7 & 105 & 103 & 100 & 105 & 88 & 58 & 30 & 6 & 13 & 16 & 25 & 235 & 173 & 170 & 164 & 158 \\
\hline 8 & 110 & 147 & 147 & 161 & 168 & 85 & 6 & 0 & 0 & 6 & 18 & 25 & 0 & 0 & 0 & 0 \\
\hline 9 & 175 & 190 & 215 & 223 & 306 & 375 & 393 & 405 & 363 & 363 & 335 & 310 & 208 & 155 & 140 & 140 \\
\hline 1 & 210 & 183 & 170 & 509 & 798 & 1073 & 620 & 660 & 830 & 605 & 840 & 650 & 520 & 843 & 710 & 860 \\
\hline 3 & 390 & 490 & 400 & 350 & 325 & 393 & 485 & 460 & 395 & 290 & 200 & 155 & 153 & 153 & 171 & 195 \\
\hline 5 & 175 & 190 & 210 & 175 & 170 & 118 & 135 & 268 & 226 & 125 & 80 & 33 & 63 & 98 & 105 & 183 \\
\hline 6 & 175 & 170 & 176 & 201 & 200 & 210 & 210 & 200 & 160 & 103 & 98 & 80 & 100 & 181 & 194 & 210 \\
\hline
\end{tabular}

a Patient nos 2, 4, 7, 8 and 9 received thalidomide during weeks 5 to 8; patients nos. 1, 3, 5 and 6 during weeks 9 to 12

$b$ Patient no. 8 received only corticotrophin; his figures give total weekly corticotrophin dosage (in international units). 
During Period 1 (first control period) the weekly steroid requirements of 8 of the 9 patients remained remarkably steady, not varying individually by more than $32 \%$. In only one patient (no. 1) was a significant change observed. Towards the end of the 3rd week his ENL became much more severe, his steroid requirements rose rapidly and the skin lesions were no longer ENL papules but resembled erythema multiforme. By the beginning of the 5th week he was slightly jaundiced, grossly anaemic, and dangerously ill. Because of the deterioration from +++ to extreme ++++ ENL, his results cannot be analysed with confidence in the 16-week schedule. However, his ENL stabilized at the severe level, and he was subsequently admitted to the 24-week schedule. The control analysis may also be extended to include Period 2 (for patients nos. 3, 5 and 6) or Period 4 (for patients nos. 2, 4, 7,8 and 9), even though some residual effect of the thalidomide is detectable in the latter period; in particular, patient no. 8 no longer required daily steroid therapy. For patients nos. 2, 3, 4, 5, 7 and 9, the greatest variation in weekly steroid requirements in the appropriate 2 periods was $56 \%$ (in patient no. 5 , in whom a determined attempt to lower the daily steroid dose while he was receiving the placebo resulted in a sharp, if short-lived, exacerbation of his ENL).

When the steroid requirements for these 8 patients (i.e. omitting patient no. 1) are analysed for the whole 16 weeks, it is seen that 7 made a dramatic response to thalidomide. All except patient no. 9 showed a progressive fall in steroid dosage while receiving the trial drug, although in only 2 cases (patients 7 and 8) was it possible completely to stop prednisolone and/or corticotrophin before the end of the thalidomide period. Table 3 compares the average weekly dose of steroid prescribed during the 4 weeks immediately preceding treatment with thalidomide, with the total steroid prescribed in the 4th (final) thalidomide week. With the exception of patient no. 9 the steroid requirements fell by more than $60 \%$, and the dosage prescribed in the 4th thalidomide week was very significantly less than the lowest weekly steroid total during the preceding period. Patient no. 9,

TABLE 3

Sixteen-week schedule: average weekly steroid dosage in the 4 weeks preceding thalidomide therapy compared with total steroid dosage prescribed in the 4th week on thalidomide

\begin{tabular}{cccc}
\hline $\begin{array}{c}\text { Patient } \\
\text { no. }\end{array}$ & $\begin{array}{c}\text { Average weekly steroid } \\
\text { dosage }^{a} \text { in the 4 weeks } \\
\text { preceding thalidomide }_{\text {therapy }}^{b}\end{array}$ & $\begin{array}{c}\text { Total steroid dosage } \\
\text { prescribed in the 4th } \\
\text { week after commencing } \\
\text { thalidomide }\end{array}$ & $\begin{array}{c}\text { Percentage fall in } \\
\text { steroid requirements }\end{array}$ \\
\hline 1 & 788 & 650 & 18 \\
2 & 126 & 49 & 61 \\
3 & 416 & 155 & 63 \\
4 & 155 & 43 & 72 \\
5 & 173 & 33 & 61 \\
6 & 205 & 80 & 94 \\
7 & 103 & 6 & 100 \\
8 & 141 & 0 & -101 \\
9 & 201 & 405 & 91 \\
\hline
\end{tabular}

a Steroid dosage expressed in $\mathrm{mg}$ of prednisolone, except for patient no. 8 which is given in international units of corticotrophin.

$b$ Weeks 5 to 8 for patients $1,3,5$ and 6 ; weeks 1 to 4 for patients $2,4,7,8$ and 9 .

${ }^{c}$ Week 12 for patients $1,3,5$ and 6 ; week 8 for patients $2,4,7,8$ and 9 . 
however, showed a marked increase in steroid requirement throughout Periods 2 and 3 ; at the same time his ENL increased in severity from +++ to ++++ , with ulceration of skin lesions and liquefaction of axillary lymph nodes; but he began to improve again from week 11 onwards, and Period 4 closely resembled Period 1.

When thalidomide was stopped at the end of the appropriate period, 6 of the 7 patients who had responded to the drug relapsed significantly and for a time required steadily increasing doses of steroid. However, the precise pattern of relapse varied. Some patients, e.g. nos. 4 and 7, after 3 weeks off the drug temporarily required steroids in excess of the Period 1 dosage, whereas Patients 2 and 3 were still well below their control-period prednisolone dosage 4 weeks af ter stopping thalidomide. Patient no. 8 had only a mild relapse, requiring no more than occasional injections of corticotrophin and his ENL stabilized at a less severe level (++ instead of $++/+++)$.

Other analyses. The total temperature scores (sum of the 28 daily scores) and the total clinical scores (sum of the 4 weekly-assessment scores) for each of the 4 periods are given in Table 4.

TABLE 4

Sixteen-week schedule: total temperature and clinical scores for each of the four 4-week periods

\begin{tabular}{|c|c|c|c|c|c|c|c|c|}
\hline \multirow{2}{*}{$\begin{array}{l}\text { Patient } \\
\text { no. }{ }^{a}\end{array}$} & \multicolumn{4}{|c|}{$\begin{array}{l}\text { Total temperature score } \\
\text { for period no. }\end{array}$} & \multicolumn{4}{|c|}{$\begin{array}{l}\text { Total clinical score } \\
\text { for period no. }\end{array}$} \\
\hline & 1 & 2 & 3 & 4 & 1 & 2 & 3 & 4 \\
\hline $\begin{array}{l}2 \\
4 \\
7 \\
8 \\
9\end{array}$ & $\begin{array}{r}4 \\
3 \\
1 \\
26 \\
18\end{array}$ & $\begin{array}{r}3 \\
9 \\
5 \\
5 \\
31\end{array}$ & $\begin{array}{r}12 \\
23 \\
26 \\
14 \\
4\end{array}$ & $\begin{array}{l}6 \\
2 \\
3 \\
2 \\
5\end{array}$ & $\begin{array}{l}51 / 2 \\
5 \\
41 / 2 \\
61 / 2 \\
10\end{array}$ & $\begin{array}{l}3 \\
31 / 2 \\
31 / 2 \\
21 / 2 \\
12\end{array}$ & $\begin{array}{l}41 / 2 \\
51 / 2 \\
81 / 2 \\
41 / 2 \\
10\end{array}$ & $\begin{array}{l}5^{1 / 2} \\
31 / 2 \\
5 \\
4 \\
7\end{array}$ \\
\hline $\begin{array}{l}1 \\
3 \\
5 \\
6\end{array}$ & $\begin{array}{r}32 \\
42 \\
0 \\
4\end{array}$ & $\begin{array}{r}77 \\
17 \\
26 \\
0\end{array}$ & $\begin{array}{r}24 \\
2 \\
1 \\
0\end{array}$ & $\begin{array}{r}56 \\
14 \\
16 \\
3\end{array}$ & $\begin{array}{l}8^{1 / 2} 2 \\
9 \\
4 \\
7\end{array}$ & $\begin{array}{l}17 \\
71 / 2 \\
61 / 2 \\
6\end{array}$ & $\begin{array}{c}10^{1 / 2} \\
31 / 2 \\
3 \\
3\end{array}$ & $\begin{array}{c}131 / 2 \\
6 \\
51 / 2 \\
61 / 2\end{array}$ \\
\hline
\end{tabular}

$a$ Patients nos. 2, 4, 7, 8 and 9 received thalidomide in period 2 ; patients $1,3,5$ and 6 in period 3 .

$b$ Temperature score derived from maximum daily temperature (1 point for every degree, or part of degree Fahrenheit above $98^{\circ} \mathrm{F}$ ).

${ }^{c}$ Clinical score-total of the 4 weekly clinical scores in each period.

Although the aim in the trial was to adjust the steroid dosage as rapidly as possible according to the needs of the individual patient, in practice there was usually a 24-h delay between the onset of a relapse and the raising of the prednisolone (or corticotrophin) intake. Similarly, when steroid requirements were falling, there was a slight delay in the cutting of dosage. Therefore it is not surprising that the clinical and temperature scores tended to be low in the period during which thalidomide was prescribed, and tended to be high in the subsequent period in which most patients relapsed. But these figures also reflect the greatly improved control of ENL achieved with thalidomide. The one exception was patient no. 9; even patient no. 1 improved slightly, according to these 2 assessments, while he was receiving thalidomide during Period 3. 
Regular fortnightly white blood cell counts were undertaken for patients nos. 1 to 8 , and the majority of results, except those for patient no. 8 , showed a polymorphonuclear leukocytosis. Considerable fluctuations occurred throughout the trial, but generally the white cell counts fell while patients were receiving thalidomide. However, in only 4 patients were the lowest counts during the period of thalidomide treatment lower than the lowest recorded during the other 3 periods of the trial.

\section{SECOND SERIES: 24-WEEK SCHEDULE}

Eight patients (nos. 1 to 7 and no. 10) were admitted to the 24-week study, which for the first 7 patients began 11 weeks after they had completed the previous (16-week) schedule. On admission, 2 (nos. 1 and 3 ) were graded,++++ 1 (no. 6) was $+++/+++$, and the other 5 were graded +++ . All 8 patients were given prednisolone orally as their principal steroid, all received occasional injections of corticotrophin, but at various times during the 24 weeks patient no. 1 also received prednisolone and hydrocortisone by injection and betamethasone by mouth.

Throughout the 6 weeks of Period 1 the severity of the ENL remained remarkably constant in all 8 patients, both clinically and in regard to steroid requirements. Therefore the results from all 8 have been accepted for analysis, the methods used being similar to those in the 16-week schedule. The results obtained from the 24-week study fully confirm the value of thalidomide in severe ENL.

Steroid requirements. The steroid requirements for the 8 patients admitted to the 24-week schedule are shown in Table 5, the dosage for 1 representative patient (no. 4) being illustrated in Fig. 2. Patients nos. 2, 4 and 5 received thalidomide in Period 2 (weeks 7 to 12 ) and patients nos. 1, 3, 6, 7 and 10 in Period 3 (weeks 13 to 18 ).

During Period 1 (weeks 1 to 6), no patient showed a variation in steroid requirement of more than 25\%. Indeed in 4 of the 5 patients who received placebo in Period 2, the greatest variation recorded during the whole of the the first 12 weeks (Periods 1 and 2 combined) was 30\%. This emphasizes the remarkable chronicity and stability of their reactions. However, patient no. 10

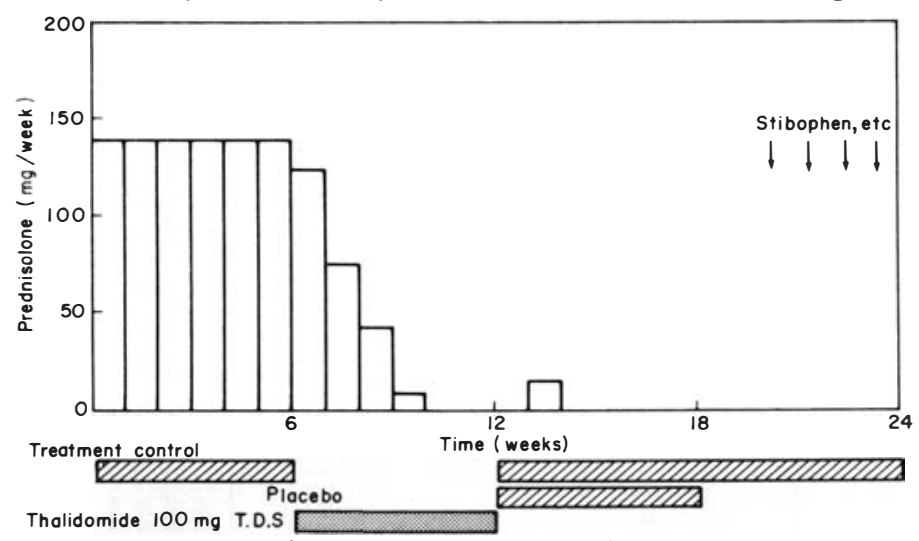

Fig. 2. Effect of thalidomide (300 mg daily for 6 weeks) on prednisolone dosage in severe, chronic erythema nodosum leprosum. Double-blind trial, 24-week schedule; patient no. 4. 
TABLE 5

Total weekly steroid dosage (expressed in $\mathrm{mg}$ prednisolone) prescribed for each of the 8 patients in the 24-week trial schedule

Total weekly steroid dosage (expressed as mg prednisolone) in each trial period

\begin{tabular}{|c|c|c|c|c|c|c|c|c|c|c|c|c|c|c|}
\hline \multirow{2}{*}{$\begin{array}{l}\text { Patient } \\
\text { no. }\end{array}$} & \multirow{2}{*}{$\begin{array}{l}\text { Control period } \\
\text { before thalidomide } \\
\text { (average weekly } \\
\text { requirements and } \\
\text { range) }\end{array}$} & \multicolumn{6}{|c|}{$\begin{array}{l}\text { Thalidomide period } b \text {; weekly } \\
\text { totals for weeks }\end{array}$} & \multicolumn{6}{|c|}{$\begin{array}{l}\text { Post-thalidomide period } \\
\text { weekly totals for weeks }\end{array}$} & \multirow{2}{*}{$\begin{array}{l}\text { Final control } \\
\text { period }^{d} \text { (average } \\
\text { weekly } \\
\text { requirements } \\
\text { and range) }\end{array}$} \\
\hline & & 1 & 2 & 3 & 4 & 5 & 6 & 1 & 2 & 3 & 4 & 5 & 6 & \\
\hline 2 & $154(140-165)$ & 130 & 93 & 84 & 70 & 50 & 53 & 95 & 96 & 105 & 105 & 105 & 105 & $110(105-111)$ \\
\hline 4 & $140(140-140)$ & 123 & 75 & 44 & 8 & 0 & 0 & 0 & 13 & 0 & 0 & 0 & 0 & 0 \\
\hline 5 & $150(140-175)$ & 140 & 78 & 21 & 0 & 0 & 0 & 0 & 0 & 0 & 0 & 0 & 0 & $23(0-50)$ \\
\hline 1 & $1032(970-1160$ & 1140 & 690 & 580 & 598 & 485 & 365 & 350 & 485 & 659 & 1083 & $790^{e}$ & $400^{e}$ & \\
\hline 3 & $305(270-350)$ & 280 & 185 & 138 & 100 & 66 & 53 & 53 & 63 & 123 & 160 & $f$ & - & \\
\hline 6 & $177(173-190)$ & 155 & 103 & 83 & 63 & 60 & 61 & 79 & 161 & 175 & 180 & 165 & 160 & \\
\hline 7 & $144(140-150)$ & 110 & 101 & 105 & 83 & 44 & 30 & 19 & 113 & 140 & 140 & 200 & 200 & \\
\hline 10 & $207(130-255)$ & 103 & 45 & 20 & 0 & 0 & 0 & 0 & 0 & 0 & 0 & 0 & 0 & \\
\hline
\end{tabular}

a Patients 2, 4 and $5=$ weeks 1 to 6 ; patients $1,3,6,7,10=$ weeks 7 to 12 , when they were receiving placebo.

$b$ Patients 2, 4 and $5=$ weeks 7 to 12 ; patients $1,3,6,7,10=$ weeks 13 to 18 .

$c$ Patients 2, 4 and 5 = weeks 13 to 18 , (when they received placebo); patients $1,3,6,7,10=$ weeks 19 to 24 .

${ }^{d}$ Patients 2, 4 and 5 only (weeks 19 to 24 ).

$e$ Patient 1 recommenced thalidomide at the beginning of week 23 .

$f$ Withdrawn from trial at week 23 for neurosurgery. 
showed a marked fall in his prednisolone dosage in weeks 11 and 12 , and therefore the significance of his subsequent results must be viewed with some reserve.

During their 6 weeks on thalidomide, all 8 patients showed a dramatic fall in their prednisolone requirements (see Table 5). It proved possible to stop steroid therapy completely in 4 patients, and the requirements of 2 others (nos. 1 and 3 ) were still falling at the end of the 6 weeks. However, the steroid requirements of nos. 2 and 6 stabilized, albeit at a low level, after 5 and 4 weeks respectively. Moreover, the weekly steroid requirements of patient no. 1 fell by approximately $670 \mathrm{mg}$ of prednisolone, whereas those of patients nos. 2 and 6 fell by only 100-120 mg. Therefore thalidomide was effective in all 8 patients (although the severity of the ENL may also have been decreasing naturally in patient no. 10), but its effectiveness, when given in a standard dose of $300 \mathrm{mg}$ daily, varied from patient to patient and bore no dose-for-dose relationship with prednisolone.

After stopping thalidomide all the patients except no. 10 relapsed to a lesser or greater degree. As judged by their steroid requirements, patients nos. 2, 6 and 7 relapsed within 1 week, nos. 1,3 and 4 during the 2 nd week, but patient no. 5 not until the 9 th week after ceasing thalidomide treatment.

The speed and severity of the relapse varied from patient to patient. Thus, patient no. 1, who at the end of the 6 weeks on thalidomide had become almost free of ENL, steadily deteriorated; by the end of the 4th week off the drug he was acutely ill again, and approximately $160 \mathrm{mg}$ of prednisolone daily failed to control the reaction. It was therefore decided, almost as a life-saving measure, to break the trial protocol, and during weeks 23 and 24 he received the same trial tablet as he was given during Period 3. Patient no. 6 reverted to his control-period steroid requirements within 3 weeks, as also did patient no. 7. However, a week later the latter developed bilateral foot-drop and therefore his steroid dosage was again increased, this time to above his pre-thalidomide control level. Patient no. 2 stabilized after 3 weeks at a lower steroid dosage than in the control period. Patient no. 3 also appeared after 4 weeks to be stabilizing at a lower dosage; however, he had suffered from ulnar neuritis before commencing thalidomide, which recurred in week 17 (when, under thalidomide his prednisolone had been cut to only $20 \%$ of his control requirements), and again in week 19 soon after stopping thalidomide. In week 22 the neuritis became much more severe, and therefore he was withdrawn from the trial. Patients nos. 4 and 5 appeared to have relatively mild relapses, which could be controlled by stibophen, i.e. their ENL had improved from Grade +++ to Grade ++. Patient no. 4 remained unchanged throughout the remainder of the trial; however, patient no. 5 suffered from a recurrence of ulnar neuritis, and was treated with corticotrophin from weeks 21 to 24. Subsequently he underwent an ulnar fasciculotomy. Only patient no. 10 had such mild ENL (Grade +) that no further treatment with either prednisolone or corticotrophin was required throughout the remainder of the trial.

Other assessments. As in the 16-week study, the temperature and clinical assessment totals tended to be lower during the period in which thalidomide was prescibed. This was most marked with patient no. 1, in whom very severe, inadequately-controlled ENL was well controlled by the trial drug. The development or recrudescence of neuritis after stopping thalidomide in 3 of the 8 patients is especially noteworthy.

As before, the white blood cell counts were variable, but in most patients fell during thalidomide treatment and rose again once treatment with the trial drug ceased. 
Toxic effects of thalidomide. The only important toxic effect was a mild allergic dermatitis which developed in 2 patients, nos. 4 and 5. The irritant rash appeared after 20 and 13 days respectively of thalidomide in the 16-week schedule; it recurred during the 24-week schedule, 9 and 2 days respectively after recommencing thalidomide treatment. Both patients developed eosinophilia. The rash was easily controlled with antihistamine drugs, and both patients considered that the improvement in their ENL resulting from thalidomide more than compensated for the slight discomfort of the sensitivity rash.

Patient no. 10 made no complaint of a rash, but perifollicular thickening of his skin was noticed while he was receiving thalidomide, and he developed a marked eosinophilia after $4 \frac{1}{2}$ weeks on the drug. Patients nos. 6 and 8 also suffered from transient rashes and eosinophilia while receiving thalidomide, but these were not undoubtedly related to the drug.

One patient complained of constipation and 2 of giddiness (although in 1 of the latter cases this was quite clearly unrelated to thalidomide). Interestingly enough, no patient complained of sleepiness during the 16-week schedule; however, 2 immediately complained of being sleepy within $24 \mathrm{~h}$ of recommencing the drug at the beginning of the appropriate periods in the 24-week schedule. The urine tests gave no evidence of any toxic effect on the kidney.

\section{Discussion}

There have been all too few controlled clinical drug trials of the treatment of established erythema nodosum leprosum (ENL). This is partly due to the difficulty in designing such trials; in many patients, ENL is either episodic or else it varies considerably in severity over short periods of time. However, it has been realized for a number of years that severe, chronic, steroid-treated ENL may remain remarkably constant in severity, and that the individual steroid dosage required just to suppress the symptoms of ENL may change only marginally over a period of many months. Recently 2 careful studies have been published (Pettit, 1967; Hastings and Trautman, 1968) in which this observation was used in the assessment of the effectiveness of clofazimine (B 663, Lamprene) in the treatment of ENL, and one of these was internally controlled, i.e. each patient acted as his own control. But as clofazimine discolours the skin and urine, a "double-blind" design could not readily be used. In the trial now reported, a complete double-blind design was introduced. Indeed the clinician in charge of the patients, who was responsible for prescribing the daily steroid dosage, was not even aware who was receiving tablet " $A$ " (the placebo) or tablet " $B$ " (the trial drug). Only the time of change-over from one tablet to the other was known, but it is doubtful if this produced any significant bias.

The results emphasize how essential careful patient-selection is. Thus, patient no. 9, although he had suffered from ENL for 17 months, had received continuous steroid therapy only for the 2 months before starting the trial. It was found that he was undergoing rapid and large changes in his steroid requirements, and in subsequent follow-up, extending over 2 years, the severity of his ENL has repeatedly waxed and waned. Therefore it is not surprising that he failed to show any improvement while receiving thalidomide. This experience suggests that patients must have been on continuous steroid treatment for a minimum of several months before they may be judged stable enough for inclusion in this kind of study. 
The initial control period, included primarily to measure the average weekly steroid requirements before giving the trial drug, should help to confirm the stability of the ENL. However, even a patient (e.g. no. 1) who appears to be stable over a long period may suddenly develop a very significant change in his reaction severity which must be detected if the trial results are to be interpreted correctly. For this reason a final control period, following the trial drug period, is essential. In this way any change in a patient's steroid requirements over the whole period of the trial may be detected, whether resulting from natural alteration with time of the severity of the ENL, or from a prolonged effect of the trial drug outlasting the actual period in which it was prescribed. In addition, the final control period will reveal the rate of relapse on cessation of the trial-drug treatment. As it may be expected that different drugs will affect ENL at different rates, it is important to choose trial periods of sufficient duration to demonstrate the full effect of the drug under investigation-with thalidomide, 4-week periods proved slightly too short. On the other hand, it is equally important that the total length of the trial must not be so great that significant natural variations in the severity of ENL occur in a high proportion of the patients. Pilot trials, carried out before the controlled trial, should give the necessary guidance on the first of these points.

The results here reported have confirmed that an alteration in steroid requirements was the most significant and objective method of assessing the effect of a drug on severe ENL. Assessments based on clinical signs and symptoms, including temperature and white blood cell counts, gave confirmatory evidence of the value of thalidomide but were less decisive. For this reason, drug-trials in mild ENL (untreated with steroids) are more difficult to design, and more subjective types of assessment have to be used. When the present study was completed at the Leprosy Research Unit, Sungei Buloh, a further double-blind, internallycontrolled trial of thalidomide was performed in patients suffering from less severe ENL. In the latter study, Pearson and Vedagiri (1969) presented a method of assessment and analysis based principally on the clinical severity of the ENL, but which also took into account the stibophen and paracetamol requirements of patients during the different trial periods.

Even though the clinical diagnosis of severe ENL is usually simple, in this study histological confirmation was obtained in every case. This was to ensure that all the reaction patients formed a homogeneous group, and also that as far as possible any controversy over classification was avoided. Indeed histology appears to be essential in any study of the effect of drugs on reactions in leprosy (Pearson and Vedagiri, 1969).

The present results confirm that thalidomide has an undoubted effect on ENL. Nine out of 10 patients showed moderate or marked improvement while they were receiving the drug. However, no dose-for-dose relationship with prednisolone was discovered. This was perhaps only to be expected. Although there is considerable evidence that thalidomide possesses immunosuppressive properties (Hellmann et al., 1965; Turk et al., 1966; Murphy et al., 1968), its mode of action is still not clear (Mouzas and Gershon, 1968) but would appear to be different from that of prednisolone and similar corticosteroids, and may be related to its action as a folic acid antagonist (Köhnlein et al., 1969). Moreover, Convit et al., (1967) have shown that patients who have not received steroids respond within $48 \mathrm{~h}$ to thalidomide whereas patients already receiving steroid undergo a sharp relapse of their ENL of up to 2 weeks' duration if the steroid is withdrawn at the same time as thalidomide is first given. 
Thalidomide was found not only to have a good effect on the general signs and symptoms of ENL and the skin lesions but also on ENL neuritis, although 3 patients developed a marked relapse of their neuritis once thalidomide was withdrawn. Sheskin et al. (1969) have carried out motor conduction velocity studies in patients with lepromatous lepra reactions (ENL). These demonstrated a dramatic improvement in the function of nerves affected by ENL neuritis as a result of treatment with thalidomide. This is particularly important as, in the past, small numbers of non-leprous patients were reported to have developed neuropathy (predominantly a sensory peripheral neuritis) after intake of thalidomide (Fullerton and Kremer, 1961). No neurotoxic effects of thalidomide have been reported to date in lepromatous patients, and it is considered that the drug's undoubted beneficial action in established ENL neuritis completely outweighs any slight theoretical risk of neurotoxicity.

Although confirming the efficacy of thalidomide in ENL, the current study does not define the optimal dosage of the drug. In order to have as few variables as possible in the trial, the intake of DDS was standardized throughout, a dosage of $100 \mathrm{mg}$ twice weekly being chosen, as the majority of patients were previously receiving this dose. We have discussed elsewhere (Waters et al., 1967; Waters, 1968) our reasons for preferring to continue effective anti-leprosy treatment without interruption in lepromatous patients suffering from ENL. Similarly, a standard dose of $300 \mathrm{mg}$ of thalidomide daily was used throughout the trial. On this dose, some patients were able to stop steroids completely, and their reactions were very adequately controlled; other patients stabilized on smaller doses of steroids, but prednisolone could not be completely withdrawn during the 4- or 6-week trial drug period. Therefore it is assumed that different patients require different minimum dosages of thalidomide just to suppress the signs and symptoms of ENL, in the same way as they require different minimum dosages of prednisolone. But whether in the treatment of ENL the minimum suppressive dosage of a drug is necessarily the optimal dosage is open to doubt. The use of prednisolone in ENL has been governed by the ready and approximately dose-related development of steroid toxicity. Apart from its teratogenic effect, thalidomide appears to be a far less toxic drug than prednisolone. In many ENL patients a dosage in excess of the minimum suppressive dose may be safely given. ENL is known to be an immune complex disease resembling the experimental Arthus phenomenon (Wemambu et al., 1969). The precise aetiology of the steroid-sensitive, relapsing nephrotic syndrome of childhood is not known, and caution is necessary in comparing it with ENL. However, it may be relevant that Barratt and Soothill (1970) have shown that in a controlled trial of cyclophosphamide given during steroid-maintained remission, a significant reduction was obtained in the incidence of relapse of the steroid-sensitive nephrotic syndrome. Therefore the possibility should be considered that in treating ENL greater long-term benefit may be obtained either by giving maintenance thalidomide in higher than minimum suppressive dosage, or by giving a combination of reaction-suppressing drugs.

Sheskin's introduction of thalidomide in the treatment of ENL is without a doubt a notable advance, and it is possible to assess the value of the different methods now available for the management of severe reactions. It is suggested that there are 3 principal alternatives, namely: (1) DDS plus steroids (usually prednisolone); (2) DDS plus thalidomide; (3) clofazimine. The first regimen suffers from the well-known disadvantages of steroid toxicity. However, it may be 
used in the majority of patients of all ages and both sexes. Steroids are very quick-acting immunosuppressives, and prednisolone is both cheap and universally available. Thalidomide is also fast acting, toxic effects are few, and the majority of patients suffer either no, or only minimal, side-effects. In our experience, sleepiness has been only a minor problem. The 2 cases of allergic dermatitis were both mild and could be controlled with anti-histamines, and we have not observed any evidence of "thalidomide neurotoxicity". But in our opinion the drug should never be given to pre-menopausal females. Indeed, because of the risk of its teratogenic effects, most leprologists consider that thalidomide should only be used under stringent conditions in well-controlled medical centres, a frustrating situation when such a cheap and otherwise relatively non-toxic drug is available.

As far as toxicity is concerned, clofazimine (Lamprene) is the safest of the 3 alternatives. Few toxic effects have been reported and no serious side-effects have been seen at the Leprosy Research Unit during 6 years' experience with the drug. Unlike the other 2 regimens it is considered that clofazimine may be safely used in domiciliary practice. It has been shown to be effective in ENL in many patients in many parts of the world. However, it acts more slowly on ENL than either prednisolone or thalidomide (it is anti-inflammatory but not immunosuppressive) and even in very high dosage may not always control the most severe reactions (see Working Party, 1969). In addition, in high dosage in light-skinned patients it causes marked pigmentation, and when Pettit (1967) used smaller doses (100 mg daily), which gave a more acceptable degree of discoloration, he found that severe ENL was not controlled. Therefore it is concluded that the treatment of severe ENL must be decided on the individual patient's circumstances. But with the recent introduction of both thalidomide and clofazimine the situation is greatly changed, and the outlook for ENL sufferers is correspondingly improved.

\section{Acknowledgements}

Grateful thanks are given to my colleagues Dr. R. J. W. Rees, National Institute for Medical Research, London, with whom this trial was jointly planned, and Dr. J. M. H. Pearson, Leprosy Research Unit, Sungei Buloh Leprosarium, for arranging the dispensing of the thalidomide and placebo tablets and for invaluable clinical help; Dr. D. S. Ridley, Pathologist, Hospital for Tropical Diseases, London, for all biopsy reports; Dr. M. K. Bhojwani, Director, Malaysia National Leprosy Control Scheme for referring suitable patients; Mrs. C. M. John for secretarial and Inche Moh. Bakri for technical assistance, and to Sister R. Sivagami and her nursing staff. Thanks are also due to Dr. H. W. von Schrader Beielstein of Chemie Grünenthal, Stolberg, West Germany, for the supply of both thalidomide and placebo. The Leprosy Research Unit, Sungei Buloh, is jointly administered by the Malaysian Ministry of Health and the [British] Medical Research Council.

\section{References}

Barratt, T. M. and Soothill, J. F. (1970). Controlled trial of cyclophosphamide in steroid-sensitive relapsing nephrotic syndrome of childhood. Lancet $i i, 479$.

Convit, J., Soto, J. M. and Sheskin, J. (1967). Thalidomide therapy in the lepra reaction. Int. J. Lepr. $35,446$.

Fullerton, P. M. and Kremer, M. (1961). Neuropathy after intake of thalidomide (Distaval). Br. med. J. ii, 855 .

Hastings, R. C. and Trautman, J. R. (1968). B 663 in lepromatous leprosy. Effect in erythema nodosum leprosum. Lepr. Rev. 39, 3 . 
Hellmann, K., Duke, D. I. and Turk, J. L. (1965). Prolongation of skin homograft survival by thalidomide. Br. med. J. ii, 687.

Köhnlein, H. E., Lemperle, G. and Kargas, J. (1969). Verlängerte Ueberlebenszeit von Homotransplantaten der Haut durch Thalidomid. Bruns Beitr. klin. Chir. 217, 165.

Mouzas, G. L. and Gershon, R. K. (1968). Correspondence. The effect of thalidomide on skin allografts in mice: survival of the grafts. Transplantation 6, 476.

Murphy, G. P., Brede, H. D., Weber, H. W., van Zyl, J. J. W., Schoonees, R., Groenewald, J. H., van Zyl, J. A., de Klerk, J. N., van Heerden, P. D. R. and Retief, C. P. (1968). Renal allotransplantation in the baboon with chemical immunosuppression. Supplement to $S$. Afr. med. J., pp. 26-37; 17 August, 1968.

Pearson, J. M. H. and Vedagiri, M. (1969). Treatment of moderately severe erythema nodosum leprosum with thalidomide-a double-blind controlled trial. Lepr. Rev. 40, 111.

Pettit, J. H. S. (1967). The treatment of erythema nodosum leprosum with B 663. A controlled study. Int. J. Lepr. 35, 11.

Ridley, D. S. and Jopling, W. H. (1966). Classification of leprosy according to immunity. A five-group system. Int. J. Lepr. 34, 255.

Ridley, D. S. and Waters, M. F. R. (1969). Significance of variations within the lepromatous group. Lepr. Rev. 40, 143.

Sheskin, J. (1965a). Thalidomide in the treatment of lepra reactions. J. clin. Pharmacol. Ther. $6,303$.

Sheskin, J. (1965b). Further observations with thalidomide in lepra reactions. Lepr. Rev. 36, 183.

Sheskin, J. (1965c). Influencia de la talidomida en la reacción leprosa. Rev. Dermatol. Venezolana 4, 210.

Sheskin, J. and Convit, J. (1966). Therapie der Leprareaktion mit Thalidomid (eine doppelblind Studie). Vorläufige Mitteilung. Der Hautarzt 17, 548.

Sheskin, J. and Convit, J. (1969). Results of a double blind study of the influence of thalidomide on the lepra reaction. Int. J. Lepr. 37, 135.

Sheskin, J., Magora, A. and Sagher, F. (1969). Motor conduction velocity studies in patients with leprosy reaction treated with thalidomide and other drugs. Int. J. Lepr. 37, 359.

Sheskin, J. and Sagher, F. (1968). The present status of thalidomide treatment in lepra reaction and leprosy. Read at Ninth International Leprosy Congress, London, Abstract in Int. J. Lepr. (1968) 36, 637.

Turk, J. L., Hellman, K. and Duke, D. I. (1966). Effect of thalidomide on the immunological response in local lymph nodes after a skin homograft. Lancet $i, 1134$.

Waters, M. F. R. (1963). Chemotherapeutic trials in leprosy. 1. Comparative trial of Macrocyclon plus dapsone and dapsone alone in the treatment of lepromatous leprosy. Lepr. Rev. 34, 173.

Waters, M. F. R. (1968). The management of erythema nodosum leprosum, with particular reference to continued dapsone therapy. Read at Ninth International Leprosy Congress, London. Abstract in Int. J. Lepr. (1968) 36,638.

Waters, M. F. R., Rees, R. J. W. and Sutherland, I. (1967). Chemotherapeutic trials in leprosy. 5. A study of methods used in clinical trials in lepromatous leprosy. Int. J. Lepr. 35, 311.

Wemambu, S.C. N., Turk, J. L., Waters, M. F. R. and Rees, R. J. W. (1969). Erythema nodosum leprosum; a clinical manifestation of the Arthus phenomenon. Lancet ii, 933.

Working Party on G 30320 or B 663-Lamprene (Geigy). Lepr. Rev. 1969. 40, 21. 